\title{
Série Mesa de Griot (ensaio visual)
}

Luanda (Patrícia Francisco) (Brasil) *

https://doi.org/10.22409/poiesis.v21i35.40525

O trabalho vem sendo elaborado por vivências no ambiente sagrado, terreiro de Umbanda e em estudos afro-brasileiros. Tem como objeto de reflexão discutir a Cultura Afro-Brasileira e sua presença na arte contemporânea proposta a partir dos trânsitos relacionais, sociais, culturais e políticos que se deram pelo mar Atlântico desde o período colonial, procurando correlacionar a natureza, a escravidão e a espiritualidade. As obras procuram apresentar a imersão espiritual, através da ambientação de "momentos" ritualísticos, construídos a partir de elementos de caráter simbólico. São recorrentemente realizadas em vídeo, fotografia, pintura, performance e instalação e organizadas em série. Dentro desse processo histórico da Escravidão que ressoa na nossa Contemporaneidade, ainda faz uma reflexão sobre o corpo, tanto o corpo negro, como o corpo da própria artista, referente à sua condição miscigenada e espiritualizada em trânsito na arte contemporânea brasileira. Luanda é o nome adotado por Patrícia Francisco para os trabalhos que elabora em coautoria com entidades espirituais afro-brasileiras.

Citação recomendada:

(PATRÍCIA FRANCISCO) Luanda. Série Mesa de Griot (ensaio visuai). Poiésis, Niterói, v. 21, n. 35, p. 125-140, jan./jun. 2020. [https://doi.org/10.22409/poiesis.v21i35.40525]

\footnotetext{
* Luanda (Patrícia Francisco) é artista plástica e cineasta, graduada em Artes Plásticas (UFRGS), Mestrado em Artes (USP), Doutoranda em Artes (UFRJ). E-mail: francisco.patricia@gmail.com
} 
Contação de histórias em 13 falas

1. mesa de ateliê, altar e contação de histórias 2. todo o meu trabalho tem sido realizado a partir do que acontece na "Mesa de Griot". 3. griot é o nome dado aos contadores de histórias de tradição oral na Cultura Africana. 4. meu trabalho apresenta muitas narrativas negras e miscigenadas, contação de histórias de origem em Franz Fanon 5. tem origem também em Achille Mbembe e na artista Grada Kilomba 6. pela quantidade de contação de histórias que recebo de espiritos de negros eu nomeei minha mesa de trabalho no ateliê de "Mesa de Griot".

7. no decorrer de minha prática artistica a própria mesa de trabalho virou um trabalho. 8. a mesa passou a ser fotografada em closes, criando uma Série. 9. fotografo os vários rastros de trabalho por qual passam essas práticas em espaço-tempo distintos. 
13. com o corpo mediunizado, Maria Conga e Pai Cipriano, orientaram que eu trabalhasse sobre o tema da "Natividade" de Jesus.(imagem 4)
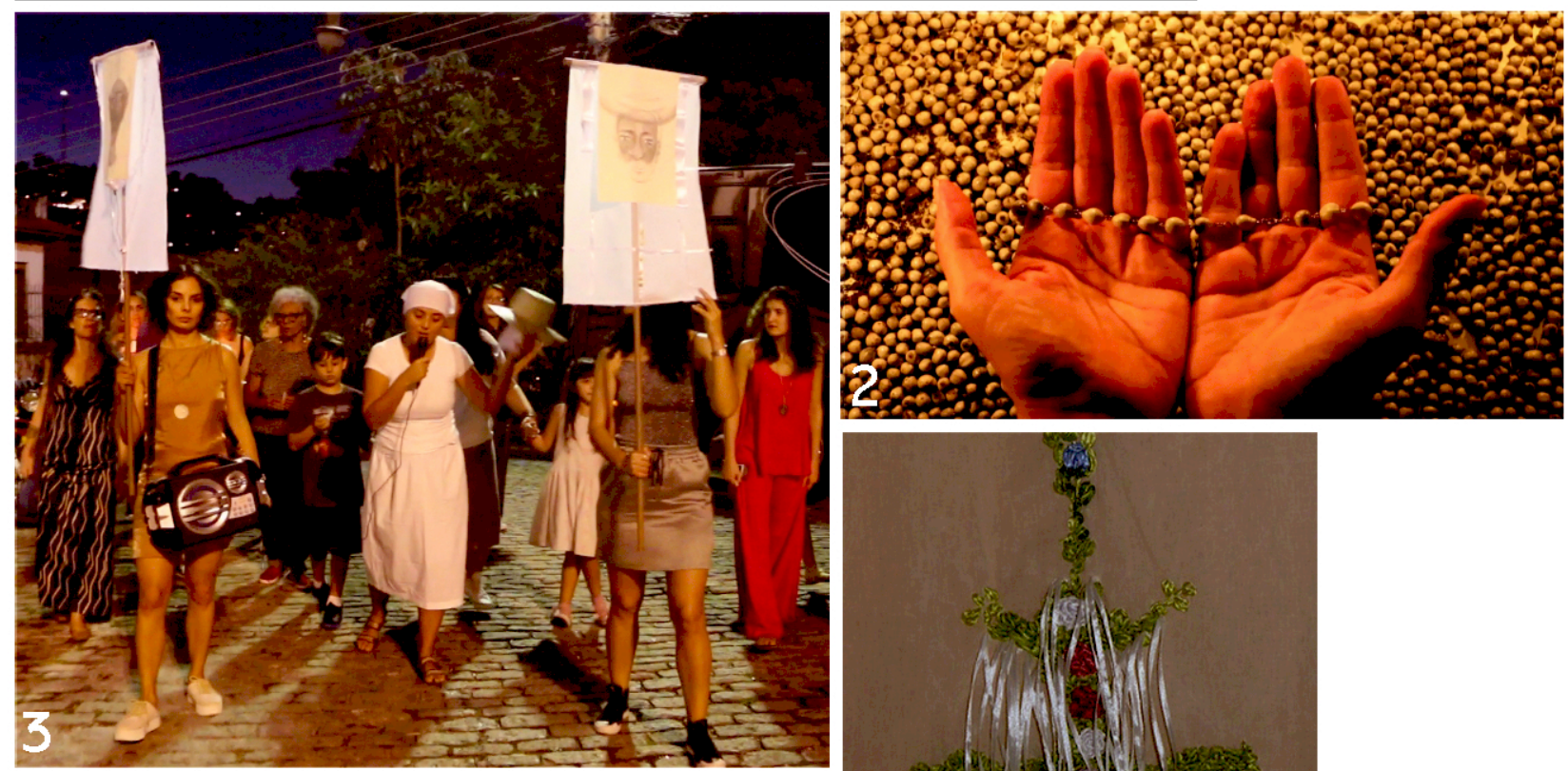

12. entre escritas de cartas foi indicado que eu realizasse uma "Procissão de Pretos Velhos" (imagem 3)

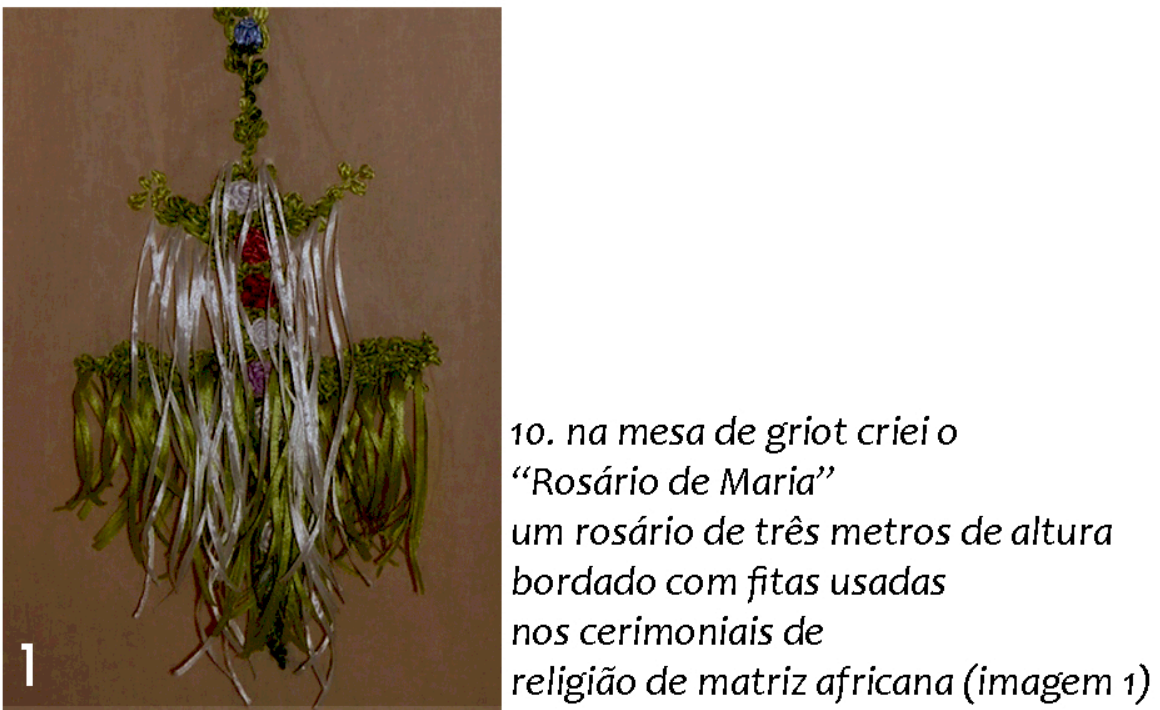



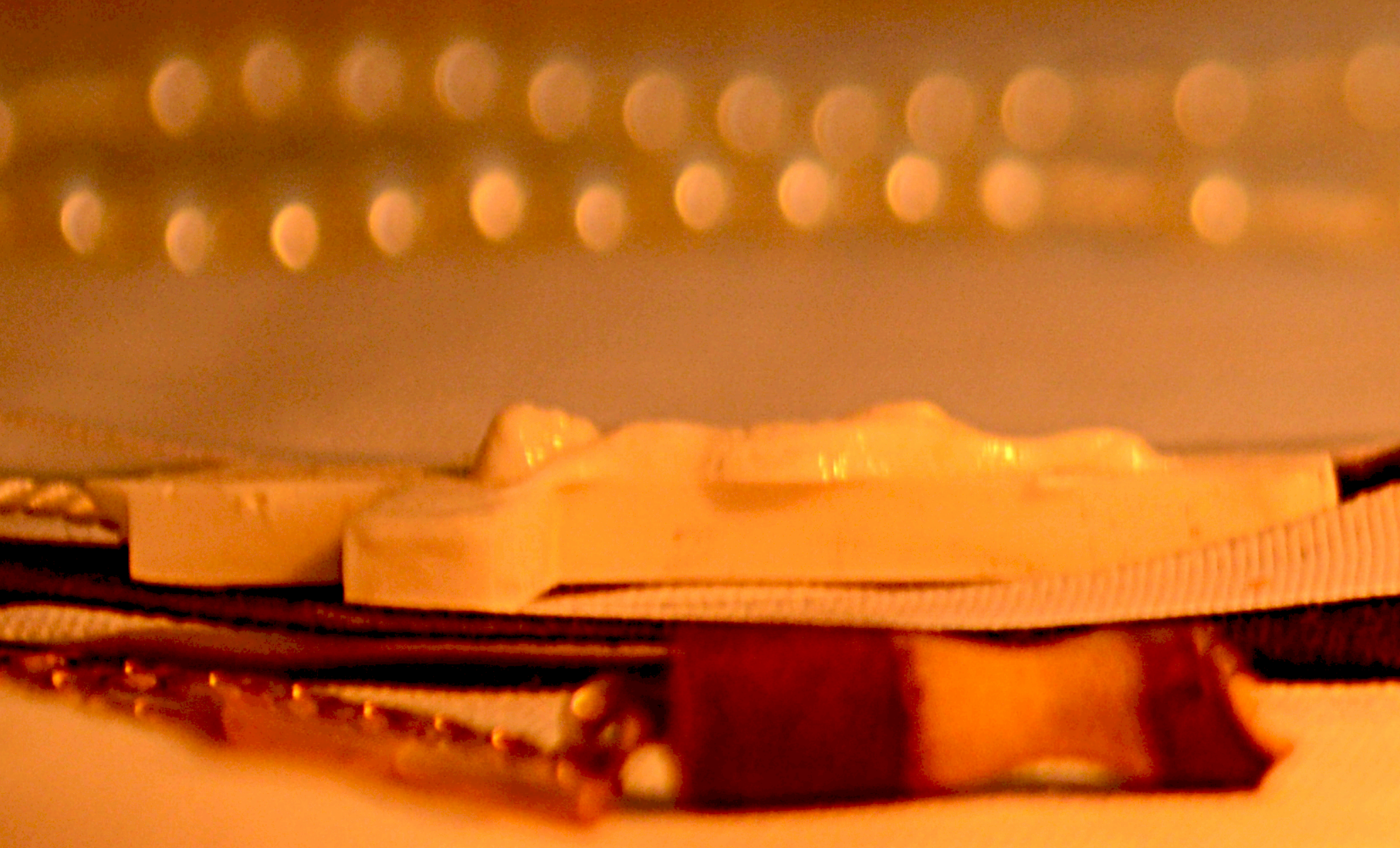


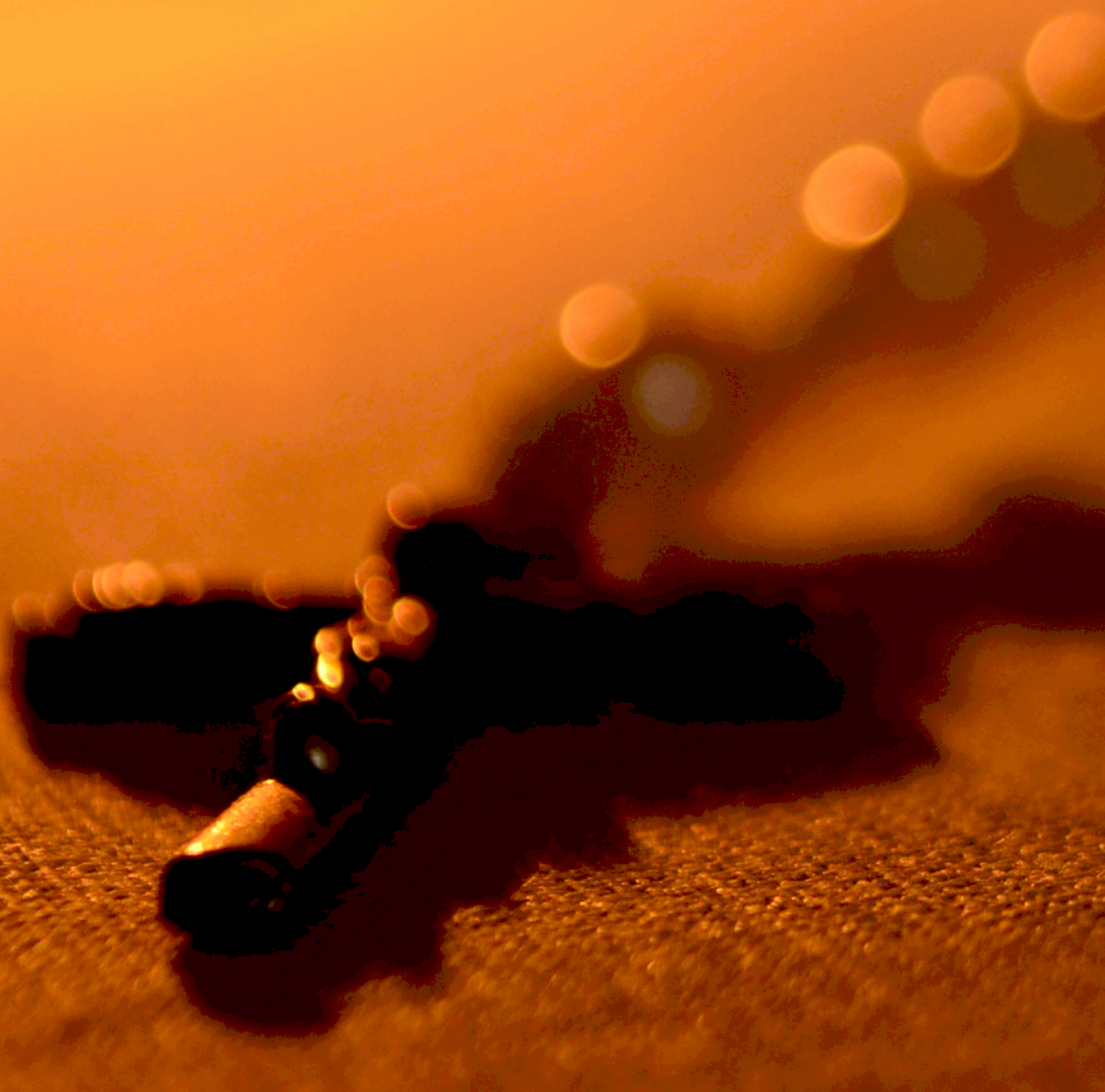




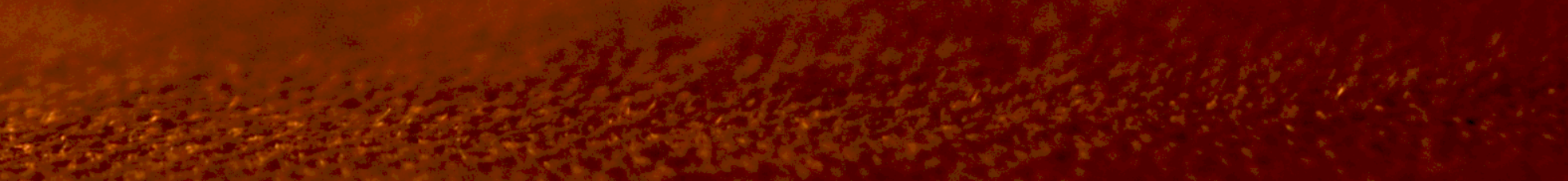



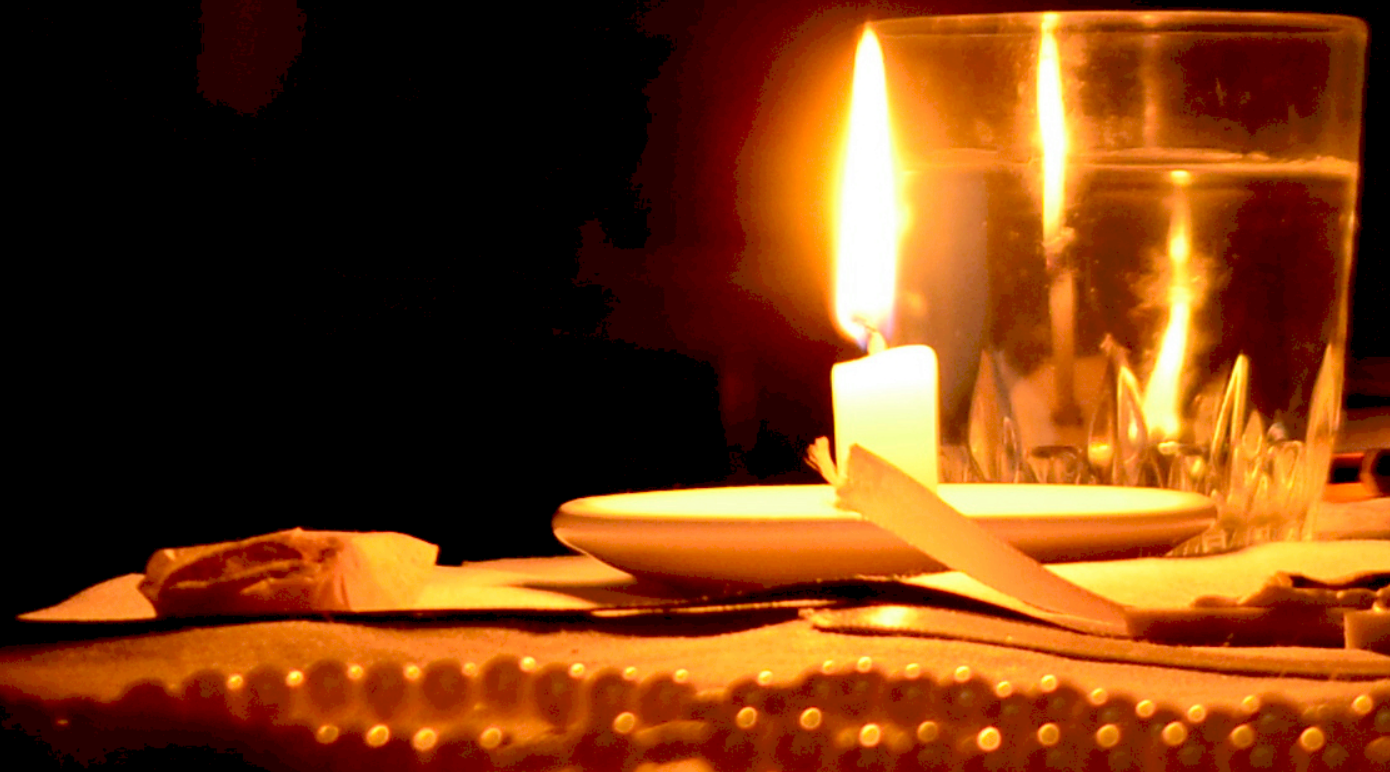


$$
{ }^{1}=
$$





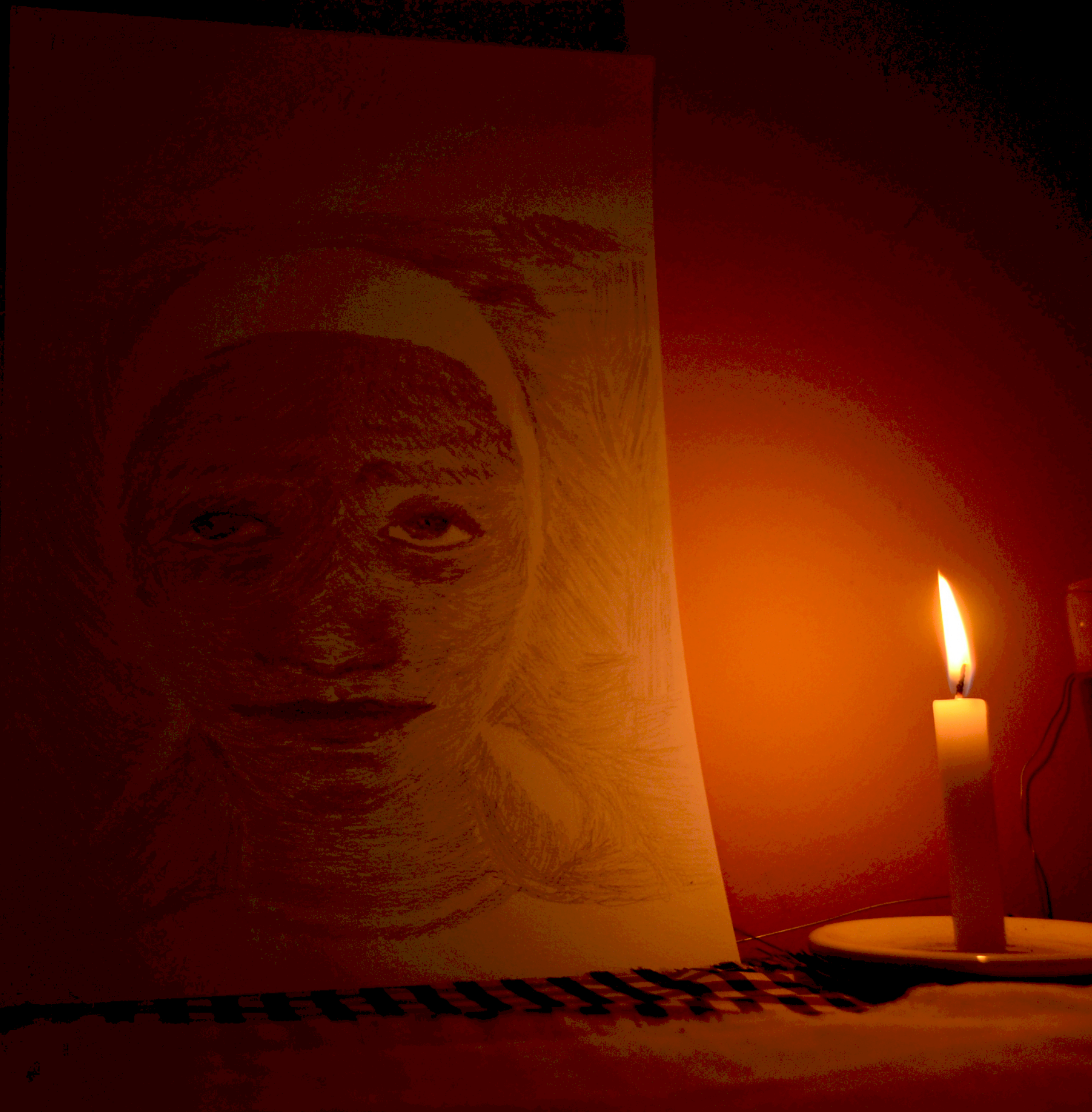




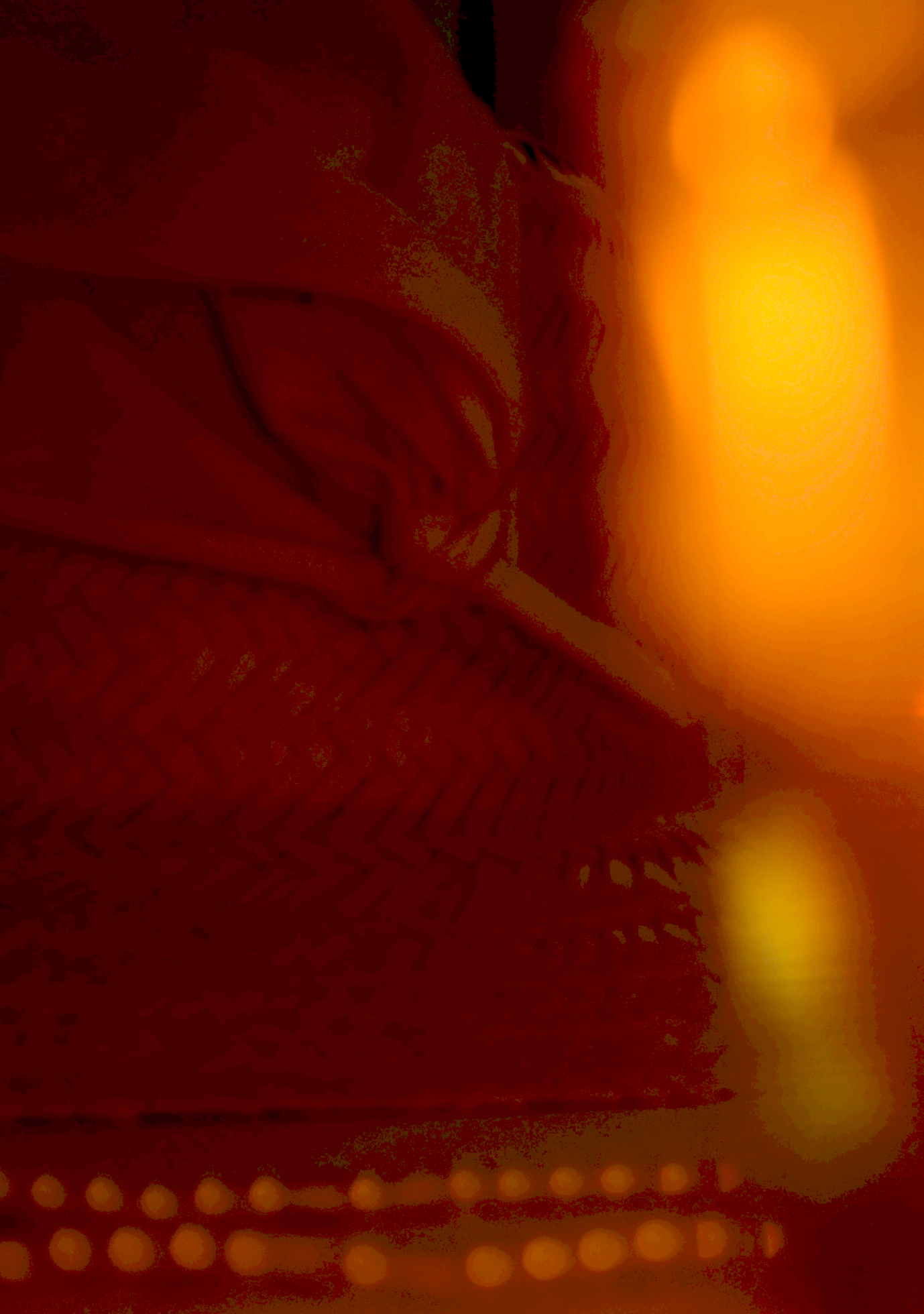




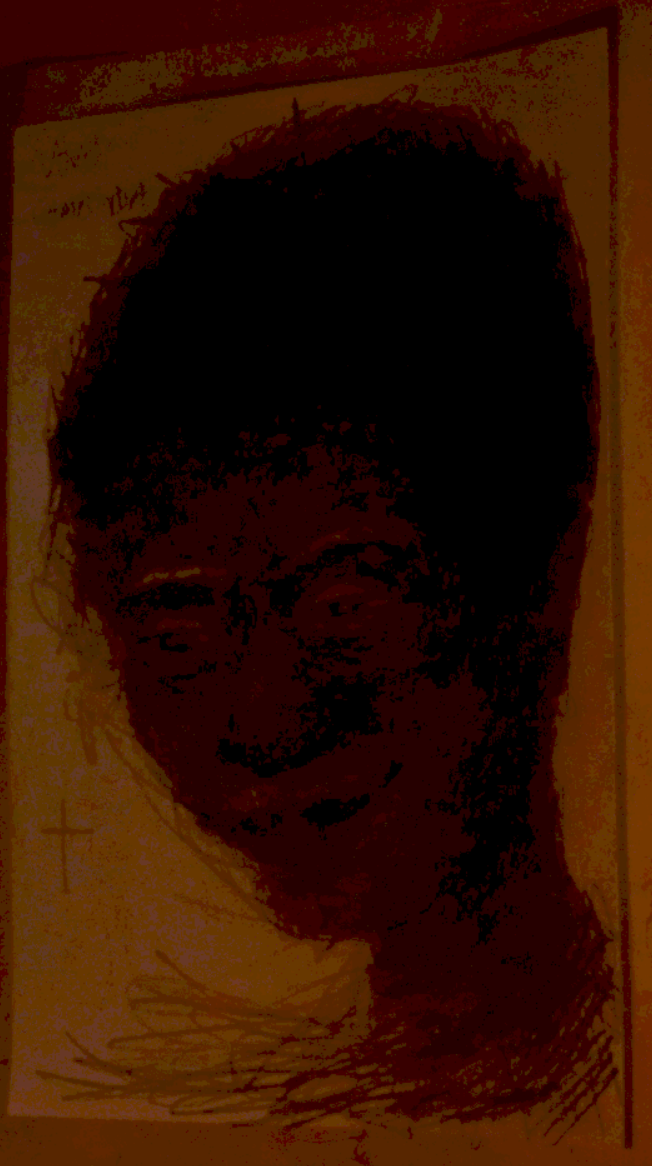

$2=\frac{3}{2}$

Cor 2 3
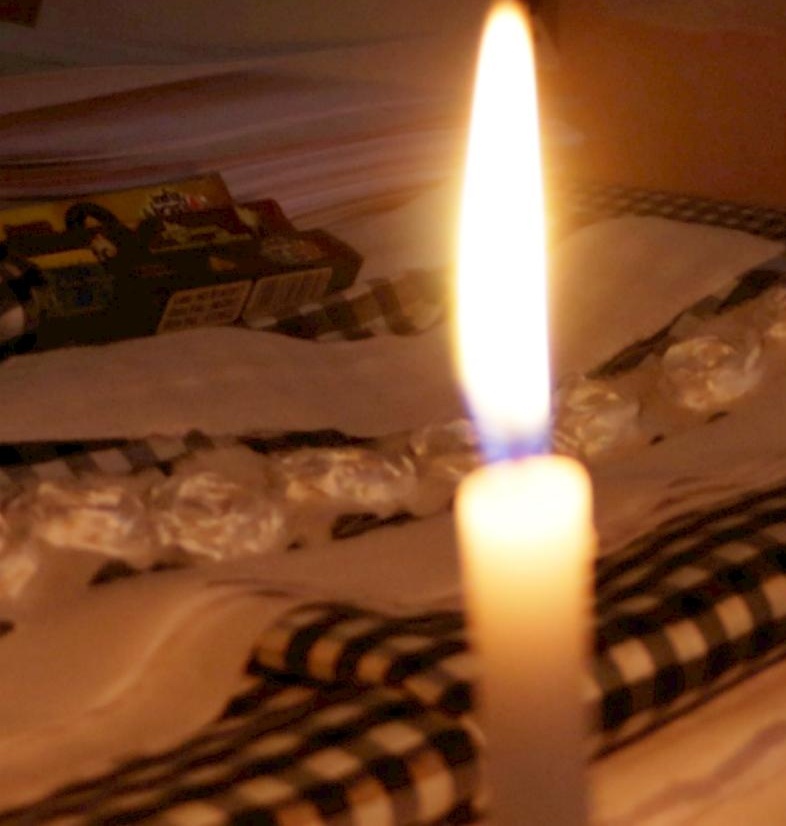


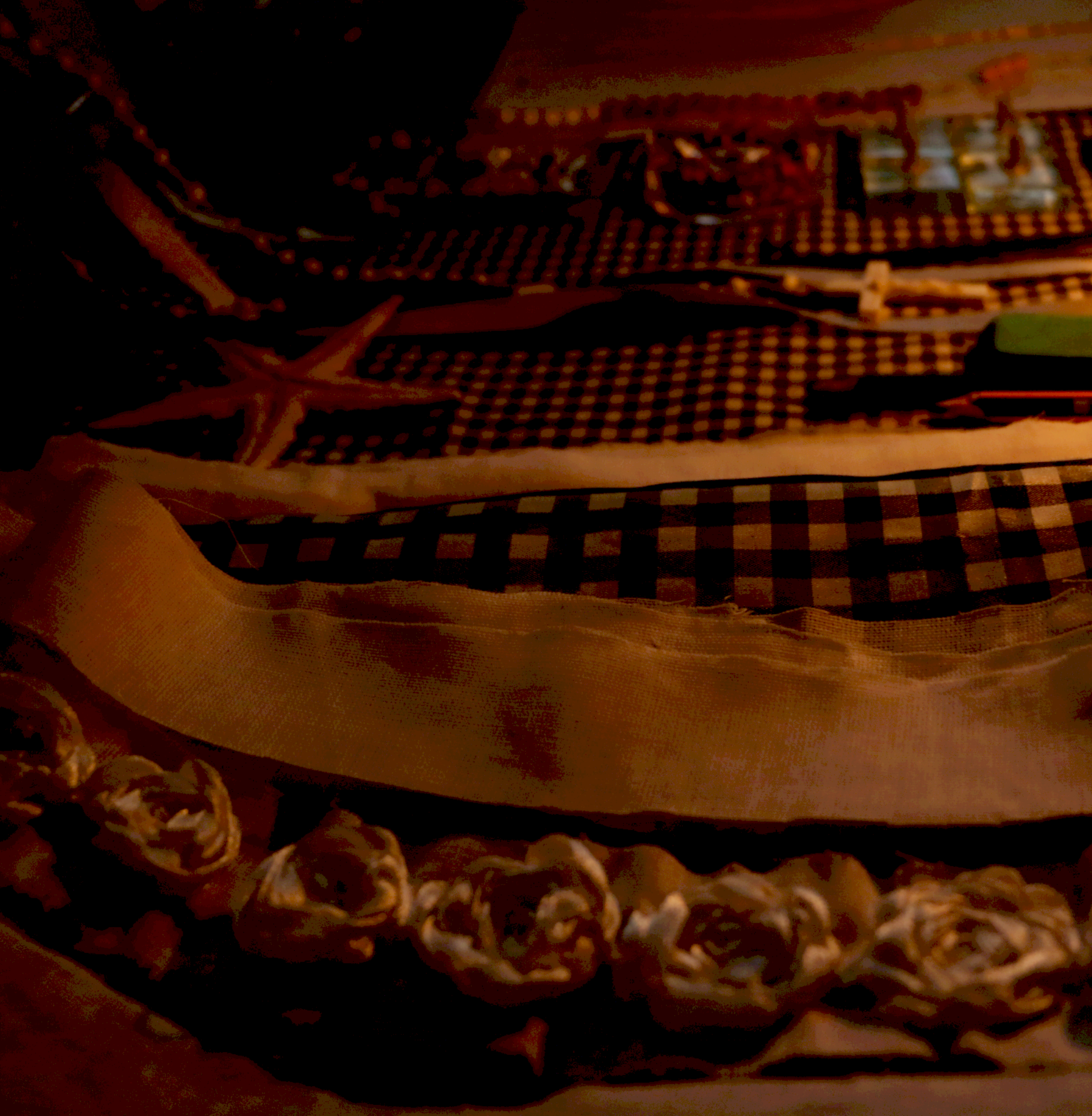



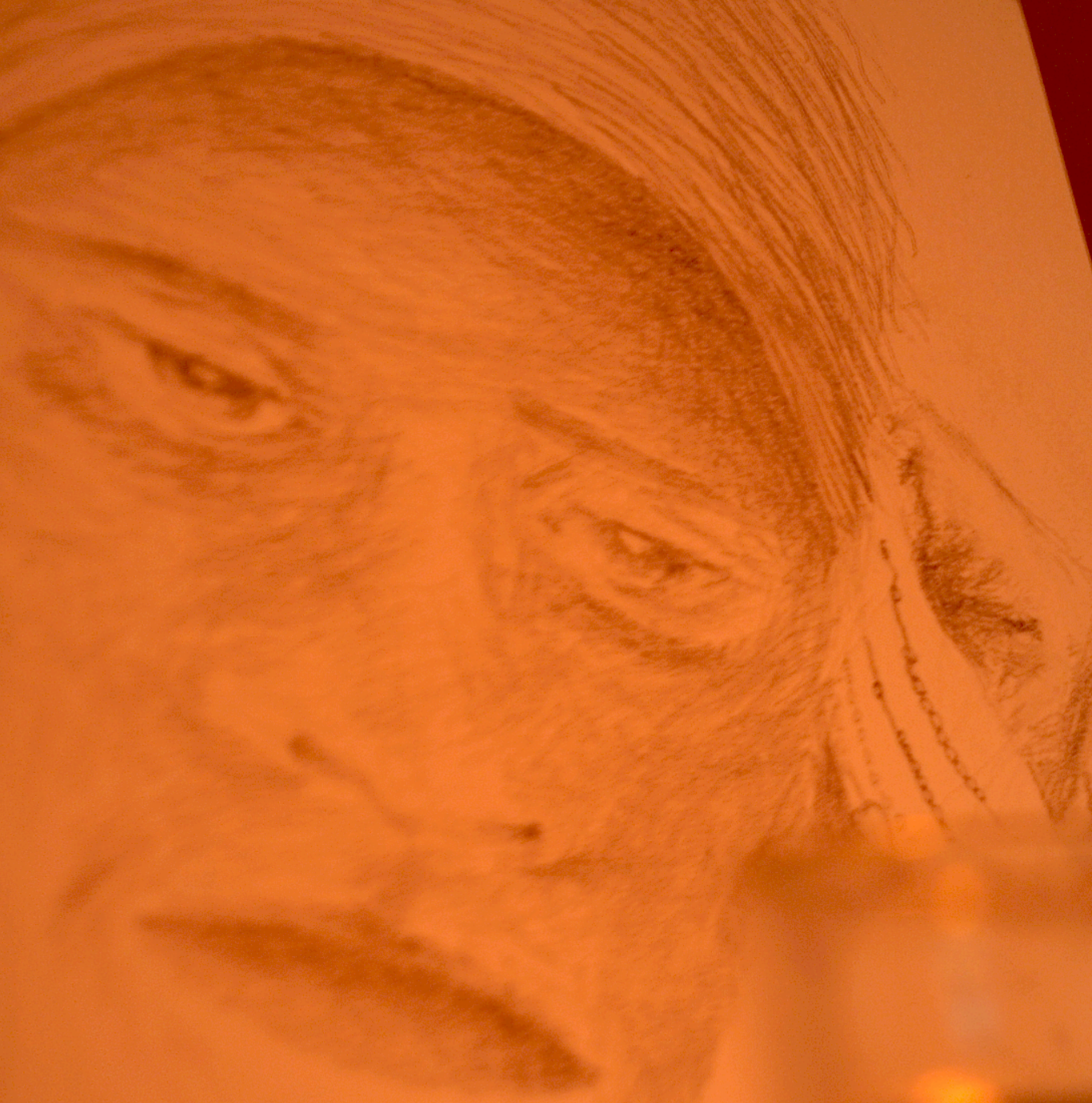